\title{
Influence of Process Parameters on Tensile Strength of the Friction Welded AA6063-T6 Joints by Box-Behnken Design Approach
}

\author{
M. Bakkiyaraj $\mathbb{D}^{1},{ }^{1}$ S. Gnanasekaran ${ }^{D},{ }^{2}$ Samson Jerold Chelladurai Samuel $\left(D,{ }^{3}\right.$ \\ K. Murugan, ${ }^{4}$ S.T. Selvamani $\mathbb{D},{ }^{5}$ and Yosef Asrat Waji $\mathbb{D}^{6}$ \\ ${ }^{1}$ Mechanical Engineering, Rajalakshmi Institute of Technology, Chennai-600124, India \\ ${ }^{2}$ Department of Mechanical Engineering, Sri Shakthi Institute of Engineering and Technology, Chinniyampalayam Coimbatore, \\ Tamil Nadu, India \\ ${ }^{3}$ Department of Mechanical Engineering, Sri Krishna College of Engineering and Technology, Coimbatore, Tamil Nadu, India \\ ${ }^{4}$ Government Polytechnic College Valangaiman, Thiruvarur, Tamil Nadu, India \\ ${ }^{5}$ Mechanical Engineering, Chennai Institute of Technology, Chennai 600069, Tamil Nadu, India \\ ${ }^{6}$ Department of Chemical Engineering, College of Biological and Chemical Engineering, \\ Addis Ababa Science and Technology University, Addis Ababa, Ethiopia
}

Correspondence should be addressed to S. Gnanasekaran; gnanasekaran1947@gmail.com and Yosef Asrat Waji; yosef.asrat@ aastu.edu.et

Received 29 November 2021; Revised 9 January 2022; Accepted 17 January 2022; Published 11 February 2022

Academic Editor: Akbar Heidarzadeh

Copyright (c) 2022 M. Bakkiyaraj et al. This is an open access article distributed under the Creative Commons Attribution License, which permits unrestricted use, distribution, and reproduction in any medium, provided the original work is properly cited.

\begin{abstract}
The present investigation demonstrates the friction welding of the AA6063-T6 joint to attain the maximum tensile strength by optimizing the parameters (friction load, friction time, and upset load) through response surface methodology. Box-Behnken design is a subset of the response surface methodology (RSM) which was employed to design the experiment numbers, and it was restricted to 15 sets. Furthermore, the inbuilt ANOVA technique was used to obtain the statistical data for the developed numerical model, and the relationship among the parameters against the output response (tensile strength) was interpreted by using the statistical data. Following this, the mechanical and metallurgical studies were done on the optimized conditions using appropriate testing and characterization equipment. The optimized conditions such as friction load $(f)$ of $3 \mathrm{kN}$ along with friction time $(t)$ of $6 \mathrm{~s}$ and an upset load of $2.5 \mathrm{kN}$ are given as input to attain the highest TS of $248 \mathrm{MPa}$. Moreover, the interface between the weld zone and the base metal of the joint was found to be broken during the tensile test when the friction load was given as $3 \mathrm{kN}$ and $4 \mathrm{kN}$, while the fracture location of the joint was found in the weld zone at the lower friction load of $2 \mathrm{kN}$. Finally, the acquired results of the optimized friction welded conditions on the AA6063-T6 joint were discussed to justify the statistical data of the numerical model, and the same results were compared to the previous research studies.
\end{abstract}

\section{Introduction}

The excellent physical properties and the proportion of light weight to higher strength of the AA6XXX wrought alloys have become the most attractive characteristics in fields such as rockets, missiles, and automotive components $[1,2]$. Moreover, the features of AA6XXX such as the ability to form complex shapes, ductile capacity, and good weldability along with corrosion resistance are able to find themselves in versatile applications. Meanwhile, the AA6063 is a special grade alloy in which the concentration of copper and silicon elements is deliberately restricted to increase corrosion resistance $[3,4]$. Hence, the AA6063 is naturally suitable to fabricate components such as heat exchanger tubes and stem valves as these components demand high corrosion resistance. Joining the aluminum alloy by the friction welding (FW) process acquires a quality joint since the FW does not melt the specimen, which is attributed to wiping out the 
fusion problems $[5,6]$. Furthermore, the rotary FW process is a suitable technique for fabricating the materials in tube and rod form. The components such as universal joint clevis, ball screw actuator, and geological core drill are examples for the rod-to-tube welded joint by FW [7]. However, the effectiveness of the joint mainly depends on the necessary heat sources and plastic deformation which are affected by FW process variables. Meanwhile, the FW process is mainly divided into two phases, namely, the friction phase and the forging phase. Furthermore, metal consolidation and burn length are proportional to each other, and they are effectively controlled by the upset load in the forging stage. In addition, the ejection of materials and metal consolidation are inversely proportional, and it is attributed to deteriorating the joint properties if the ratio exceeds the permissible limit [8-10]. Hence, the phenomenon with reference to the FW process is monitored and efficiently controlled by the parameter optimization to attain the defect-free quality joint.

The optimization methods such as artificial neural network (ANN) and RSM are extensively used in various fabrication processes including the welding methods to optimize the process parameters [11-13]. The comparative study between the RSM and ANN techniques also successfully demonstrated the parameter optimization of friction spot welding, and the study concludes that the obtained output response (tensile strength) with reference to RSM and ANN methods was found to be similar [14]. Bakkiyaraj et al. [15] investigated the FW of the MSS joint to increase the TS via the RSM parametric optimization and reported that the TS of the joint is mostly affected by the variation in rotation speed. Palanivel et al. [16] studied the FW parametric effects on the microstructure grain size of the titanium tube joint using RSM-based optimization. The grain fragment is predominating the rises of heat when the rotation speed and friction time are increased to a certain level which leads to reduction in grain size. Kimura et al. [17] showed that the friction time has more impact on the TS since the fluctuation in TS was found to be high concerning the variation in friction time. Moreover, the effect of forging time on the joint properties was found to be lower than that of friction-related parameters. Furthermore, the RSM technique is a widely used one, and it has several methods to generate the design matrix with reference to problem requirements [18-21]. This investigation presents the Box-Behnken-based RSM approach to optimize the FW conditions of the AA6063-T6 joint since the literature on Box-Behnken-based optimization studies in the welding process was found to be very limited. In addition, the FW of the AA6063 joint and the effect of welding conditions on the joint properties were also investigated in detail at the optimized conditions.

\section{RSM and Experimentation}

The Box-Behnken design is a familiar technique that is an integral part of the RSM and used to effectively reduce the number of experiments in such a way that the present investigations contain 15 sets of experiments. Box-Behnken design approach reduces the experiments when compared with central composite design. In addition, the points used outside other than middle points are also very close to the center level. Hence, the number of middle points used in the design matrix is also restricted to a minimum number. This Box-Behnken design-based investigation has 3 middle points and 12 outside points. The variables such as friction load $(f)$, friction time $(t)$, and upset load $(p)$ are the important parameters $[17,18,22]$, and these have been rotated to generate the design matrix in accordance with process windows. Meanwhile, the rotation speed is kept constant at $1800 \mathrm{rpm}$ for all 15 sets of experiments. Prior to that, the macroanalysis of the fabricated trail joints is carried out to arrive at the process window and its descriptions are presented in Table 1. The range of parameters was lower than that of the process window, which resulted in very poor ponding. The higher range outside the process window is also attributed to the noticeable crack at the joint interface. Hence, the process window concerning the permissible limits is shown in Table 2. The base metals AA6063-T6 properties are listed in Table 3 , and it has the following geometries: $70 \mathrm{~mm}$ long and $16 \mathrm{~mm}$ in diameter. The grade of aluminum alloy was ensured by evaluating the volume fractions of the elements present in the aluminum matrix using optical emission spectroscopy, and the results were $\mathrm{Si}$ 0.5, Fe-0.32, Cu-0.1, Mg-0.1, Cr-0.08, Zn-0.09, and Ti-0.1, and the balance was aluminum.

The rubbing surface of the AA6063-T6 specimens is machined by the facing process in a lathe machine, and then, it is cleaned with acetone. Following this, the FW experiments were conducted to fabricate three joints in each welding condition using an FW machine (model) and its welded specimens are presented in Figure 1. Then, the fabricated joints were subjected to a tensile test (ASTM E8) to evaluate the effectiveness of the joint using a tensile tester as the ASTM E8 procedure was followed to prepare the tensile specimens. The average value of the experimentally evaluated TS and the predicted TS using a numerical equation is presented in design matrix (Table 4). The optimized conditions of FW joints have been taken into metallurgical investigations for correlating the observations with the obtained TS. To reveal the macrostructure and microstructure of the welded specimen, the interface of the joint is polished and etched with the solution (concentric Keller reagent) as per the standard. Finally, the metallurgical (macro and micro) investigation was carried out using an optical microscanner.

\section{Evaluation of Statistically Developed Model}

The statistical data were derived using ANOVA tool are presented in Table 5, as the experimented TS values are given as input to the Design Expert software. The developed numerical model is at a satisfactory level since the obtained model $p$ value is 0.0002 with an $F$ value of 88.89 . Furthermore, the terms relating to the empirical model such as $F, P$, $F T, F^{2}, T^{2}$, and $P^{2}$ are identified at a substantial level as their values fall (less than 0.05 ) in the permissible limits [22-24]. Meanwhile, the $R^{2}$ predicted and adjusted values are found to have a reasonable agreement with each other since their 
TABLE 1: Macroanalysis of the joint fabricated by the trail method.

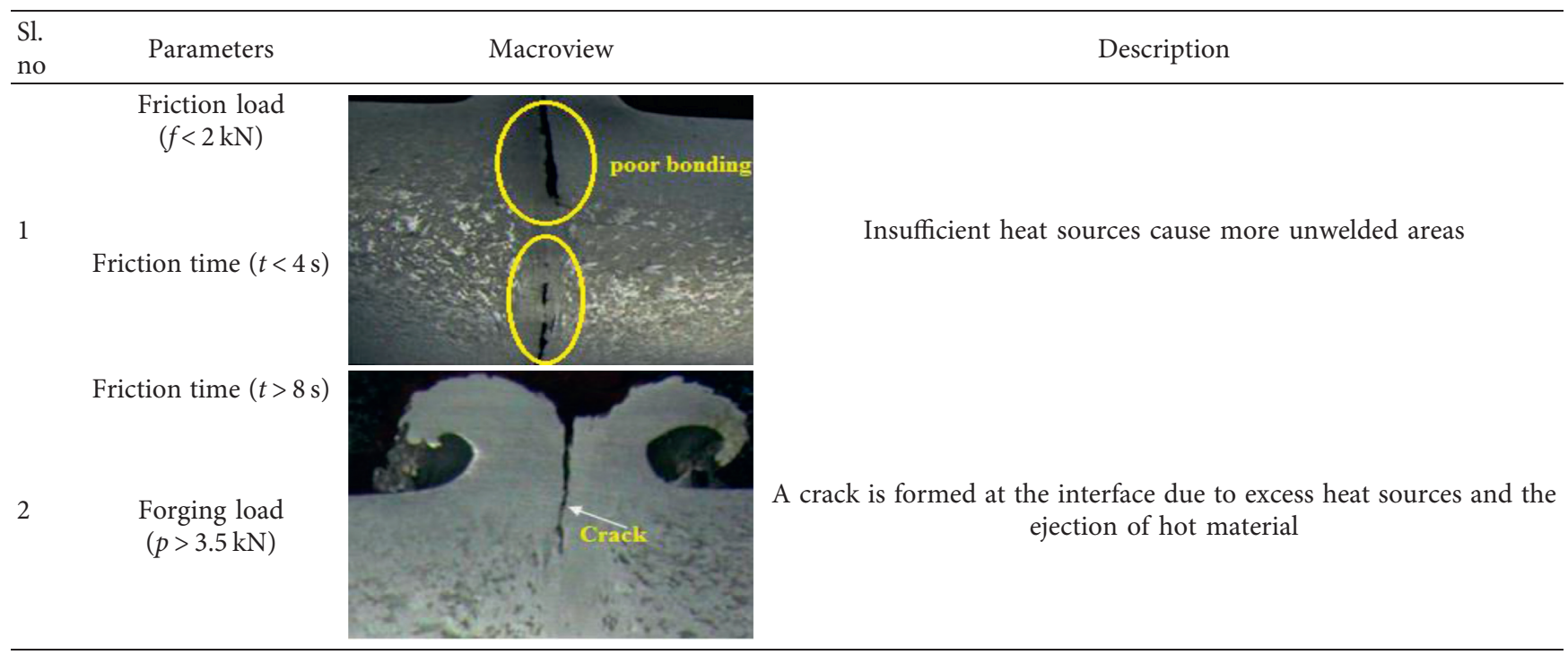

TABLE 2: FW process window.

\begin{tabular}{|c|c|c|c|c|c|}
\hline \multirow{2}{*}{ Parameter } & \multirow{2}{*}{ Notation } & \multirow{2}{*}{ Unit } & \multicolumn{3}{|c|}{ Level } \\
\hline & & & -1 & 0 & 1 \\
\hline Friction load & $\mathrm{f}$ & $\mathrm{kN}$ & 2 & 3 & 4 \\
\hline Friction time & $\mathrm{t}$ & $S$ & 4 & 6 & 8 \\
\hline Upset load & $\mathrm{p}$ & $\mathrm{kN}$ & 1.5 & 2.5 & 3.5 \\
\hline
\end{tabular}

TABLE 3: Base metal properties.

\begin{tabular}{lccc}
\hline Material & Tensile strength $(\mathrm{MPa})$ & Elongation $(\%)$ & Hardness $(\mathrm{HV})$ \\
\hline AA6063 & 286 & 12 & 72 \\
\hline
\end{tabular}
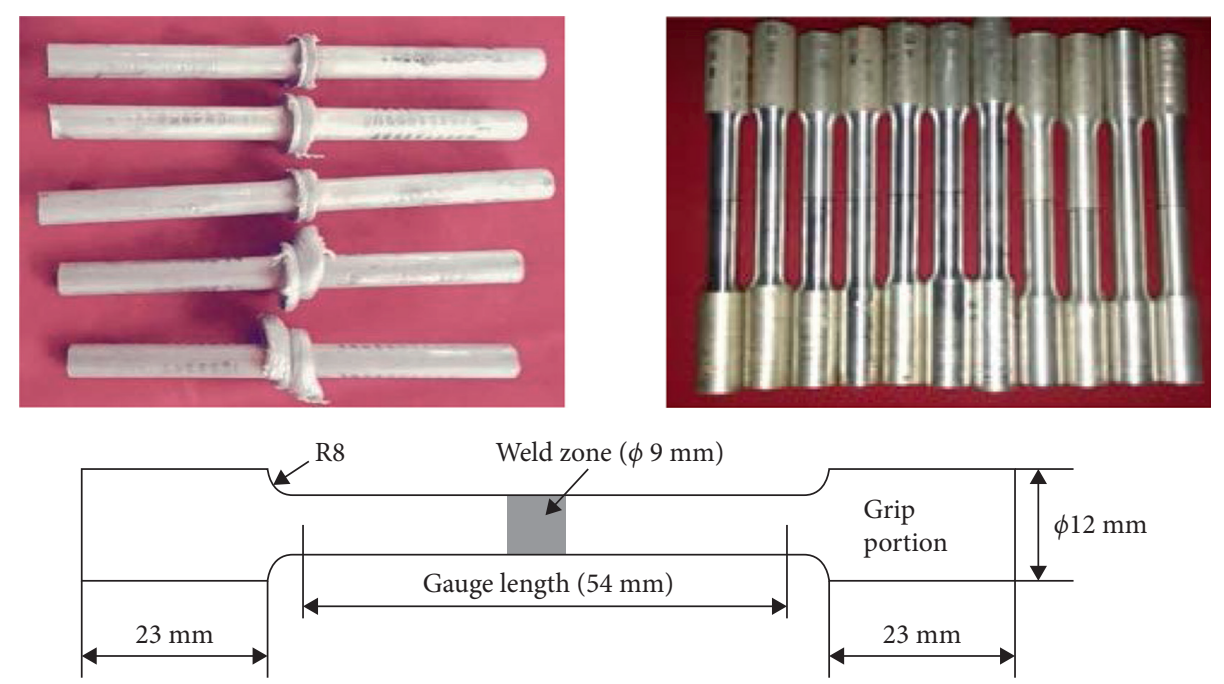

Figure 1: FW welded joints and tensile specimens. 
TABle 4: Design matrix.

\begin{tabular}{|c|c|c|c|c|c|c|c|c|}
\hline \multirow{3}{*}{ Sl. no. } & \multicolumn{6}{|c|}{ Parameter range } & \multicolumn{2}{|c|}{ Tensile strength $(\mathrm{MPa})$} \\
\hline & \multicolumn{3}{|c|}{ Code } & \multicolumn{3}{|c|}{ Actual } & \multirow{2}{*}{ Actual value } & \multirow{2}{*}{ Predicted value } \\
\hline & $F$ & $t$ & $P$ & $f$ & $t$ & $P$ & & \\
\hline 1 & -1 & -1 & 0 & 2 & 4 & 2.5 & 170.15 & 164.235 \\
\hline 2 & 1 & -1 & 0 & 4 & 4 & 2.5 & 182.2 & 181.115 \\
\hline 3 & -1 & 1 & 0 & 2 & 8 & 2.5 & 152.02 & 153.145 \\
\hline 4 & 1 & 1 & 0 & 4 & 8 & 2.5 & 183.43 & 188.345 \\
\hline 5 & -1 & 0 & -1 & 2 & 6 & 1.5 & 88.09 & 90.67 \\
\hline 6 & 1 & 0 & -1 & 4 & 6 & 1.5 & 156.8 & 155.55 \\
\hline 7 & -1 & 0 & 1 & 2 & 6 & 3.5 & 155.6 & 158.85 \\
\hline 8 & 1 & 0 & 1 & 4 & 6 & 3.5 & 149.64 & 147.06 \\
\hline 9 & 0 & -1 & -1 & 3 & 4 & 1.5 & 109.8 & 113.145 \\
\hline 10 & 0 & 1 & -1 & 3 & 8 & 1.5 & 128.1 & 124.435 \\
\hline 11 & 0 & -1 & 1 & 3 & 4 & 3.5 & 152.05 & 155.705 \\
\hline 12 & 0 & 1 & 1 & 3 & 8 & 3.5 & 144.9 & 141.555 \\
\hline 13 & 0 & 0 & 0 & 3 & 6 & 2.5 & 239 & 244.2 \\
\hline 14 & 0 & 0 & 0 & 3 & 6 & 2.5 & 245 & 244.2 \\
\hline 15 & 0 & 0 & 0 & 3 & 6 & 2.5 & 248.6 & 244.2 \\
\hline
\end{tabular}

TABle 5: Statistical data.

\begin{tabular}{lcrr}
\hline Source & & $\begin{array}{c}\text { Tensile strength (MPa) } \\
\text { Quadratic model }\end{array}$ & F Value $(88.89)$ \\
Model & $p$ value $(<0.0005)$ & Lack of fit & $R^{2}$ \\
$\mathrm{~F}$ & 0.0018 & Adjustable $R^{2}$ & 0.3934 \\
$\mathrm{~T}$ & 0.7574 & Predicted $R^{2}$ & 0.9938 \\
$\mathrm{P}$ & 0.0014 & Adequate precision & 0.9215 \\
$f * t$ & 0.1796 & - & 30.34 \\
$f * p$ & 0.0018 & - & - \\
$t * p$ & 0.0953 & - & - \\
$f^{2}$ & 0.0001 & - & - \\
$t^{2}$ & $<0.0001$ & - \\
$p^{2}$ & $<0.0001$ & & - \\
\hline
\end{tabular}

estimated values are closer to one. In addition, the difference among the various $R$ squared value is also found within the acceptable limits of less than 0.02 . The developed mathematical equation to attain the TS of the FW AA6063-T6 joint is given below in the form of a coded value, as the equation reveals that the model processing order is quadratic analysis.

$$
T S=244.20+13.27 f-0.7150 t+14.92 p+4.83 f t-18.67 f p-6.36 t p-34.21 f^{2}-38.03 t^{2}-72.46 p^{2}
$$

The terms, namely, $f, p, \mathrm{ft}$, and $\mathrm{t}^{2}$ have a positive impact on the TS of the AA6063-T6 joint since their coefficient values are positive. Likewise, the terms such as $t, f b, t b, f^{2}$, and $p^{2}$ have a negative impact on the output response. Furthermore, the 2-dimensional graph (Figure 2) that correlates the calculated and experimented TS values has good agreement and the average deviation is found to be less than $2 \%$. The statistical data present the adequate precision value of 30.34 which is well ahead of the minimum required level [25-27]. Normally, the purpose of the desirability function is to attain the best range of parameters from outside of the zero level limits. Maximum desirability is achieved when the friction time is $5 \mathrm{~s}$ with the friction load of $2.5 \mathrm{kN}$. On the other hand, increasing the desirability function closer to unity is attributed to minimizing deviation of the output response at lower and higher levels when compared to the middle level.

\section{Optimized Parameter}

The calculated TS values using code-based numerical relation and the experimented TS are presented in Table 4. Moreover, the 3-dimensional surface plots between the process variables $(f, t$, and $p)$ drawn concerning the TS using the Design Expert software are depicted in Figure 3. The apex of the plots represents the maximum attainable TS of $248 \mathrm{MPa}$ at the increased friction load $(f)$ of $3 \mathrm{kN}$ along with 

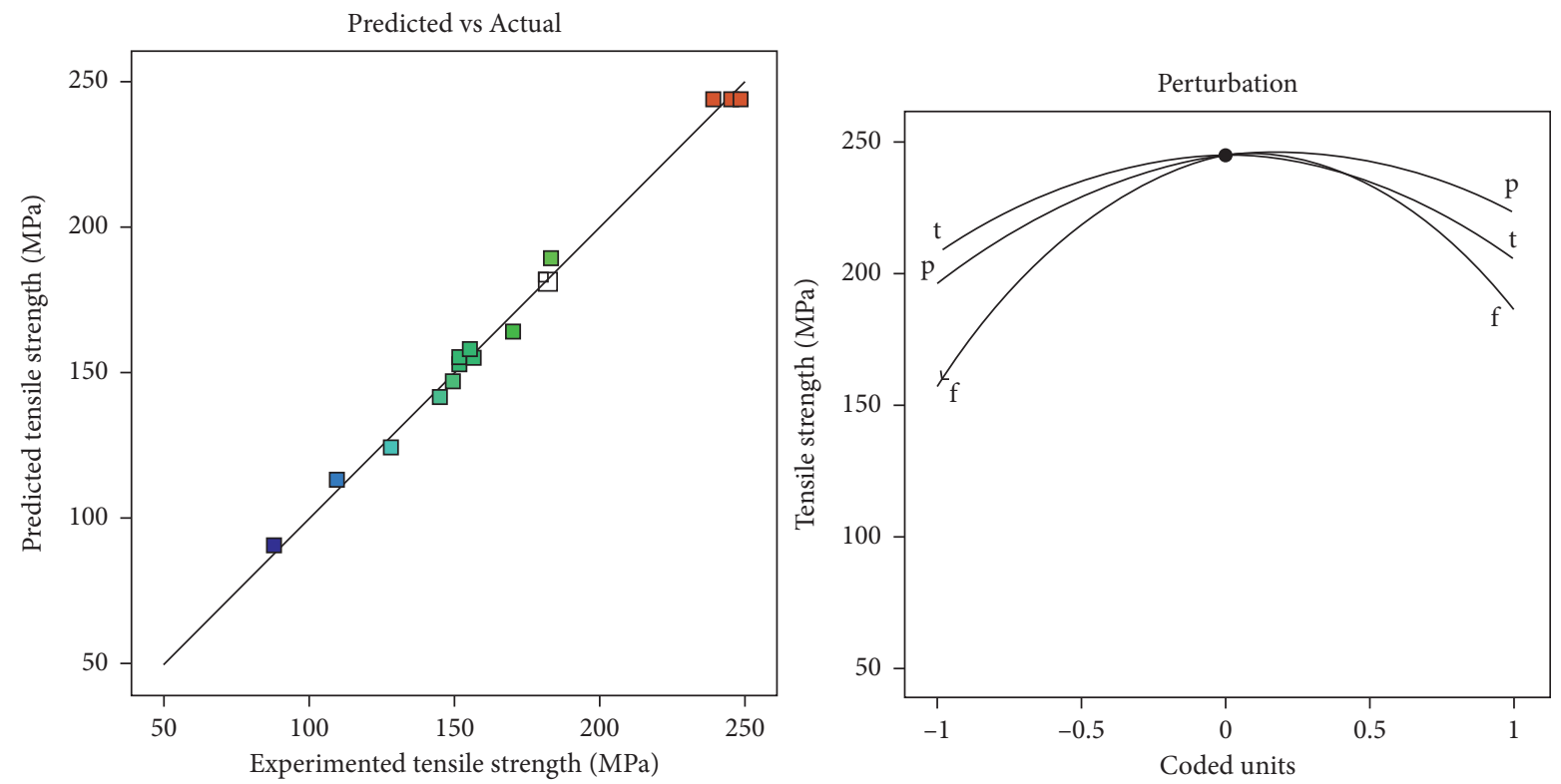

Figure 2: Correlation and perturbation graph.

friction time $(t)$ of $6 \mathrm{~s}$ and an upset load of $2.5 \mathrm{kN}$. It is concluded that the higher joint efficiency was achieved when the higher friction load $(f)$, higher friction time $(t)$, and comparatively shorter upset load $(p)$ were used as inputs during the fabrication of the AA6063 joint.

Meanwhile, the perturbation graph reveals that the TS value is proportional to $f, t$, and $p$ from the lower level to the middle level of FW conditions. Thereafter, the FW conditions on TS are diverted to an inverse route from middle level to higher level. From this observation, it is concluded that friction load on the TS of the AA6063-T6 joint is found to be more effective since the value of the output response is highly fluctuated when the friction load is varied. In addition, to validate the reliability of the developed numerical model, testament experiments have been conducted, and the range of parameters used in this testament is not used in the design matrix. At the same time, the set of parameters fits with the process windows. Moreover, the testament results listed in Table 6 with reference to the TS response are found to be very satisfactory, and the maximum deviation between the empirically calculated TS and the experimented value is very small.

\section{Metallurgical Studies under Optimized Conditions}

This discussion is constructed to detail the effect of variation in friction load on the TS of the AA6063-T6 joint since the friction load is identified to be the most influential parameter on TS. The macrostructure of the joint investigated under the various friction loads $(f)$ using a digital microscope is presented in Figures 4(a) -4 (c). The variation in the geometry of the outer flash is clearly noticed in the macroimage as the variation in friction load $(f)$. The macrostructure represents poor bonding at the outer edge of the joint made at the friction load of $2 \mathrm{kN}$. Meanwhile, the volume of the outer flash of the joint is found to be greater than at the friction load of $3 \mathrm{kN}$. At the same time, the bonded area was also found to be higher; hence, the TS of the joint is maximum. On the other hand, macrostructure represents the fine boding with comparatively less outer flash at a friction load of $4 \mathrm{kN}$. Hence, the plasticized materials were consolidated well even at the higher friction load since the upset load was kept at a minimum of $2.5 \mathrm{kN}$.

The base metal microstructure and microstructure of the welded specimen at various friction loads are presented in Figures 5(a)-5(d). The AA6063-T6 base metal portraits (Figure 5(a)) coaxial grain with an average size of $147 \mu \mathrm{m}$. Furthermore, the grains seen in the welded joint are found to be finer since the interface of the joint is influenced by severe dynamic recrystallization.

However, the difference in the grain variation was also noticed with reference to the changes in friction load. At friction loads of $2 \mathrm{kN}, 3 \mathrm{kN}$, and $4 \mathrm{kN}$, average grain sizes of $28 \mu \mathrm{m}, 12 \mu \mathrm{m}$, and $16 \mu \mathrm{m}$ are determined, respectively. The effect of friction load on grain size increases with finer reduction in grains. This is attributed to the fine initiation of grain fragments during the welding process, and the grain fragments dominate the frictional heat even at higher friction loads [28, 29]. Hence, the joint displayed the maximum joint efficiency. However, the marginal grain coarsening effect at the high friction load might be due to the delayed cooling during the welding. It is clearly understood from the stress-strain graph (Figure 6) that the coarsening effect at high friction load is attributed to increasing the elongation rate and comparatively decreasing the strength of the joint to $227 \mathrm{MPa}$. Furthermore, the elongation rate and tensile strength were estimated to be lower values at a friction load of $2 \mathrm{kN}$ as the macrostructure of the joint showed a minor crack in the weld line. Meanwhile, the optimum friction load of $3 \mathrm{kN}$ of the joint showed a TS of $248 \mathrm{MPa}$ with $10.5 \%$ strain. 

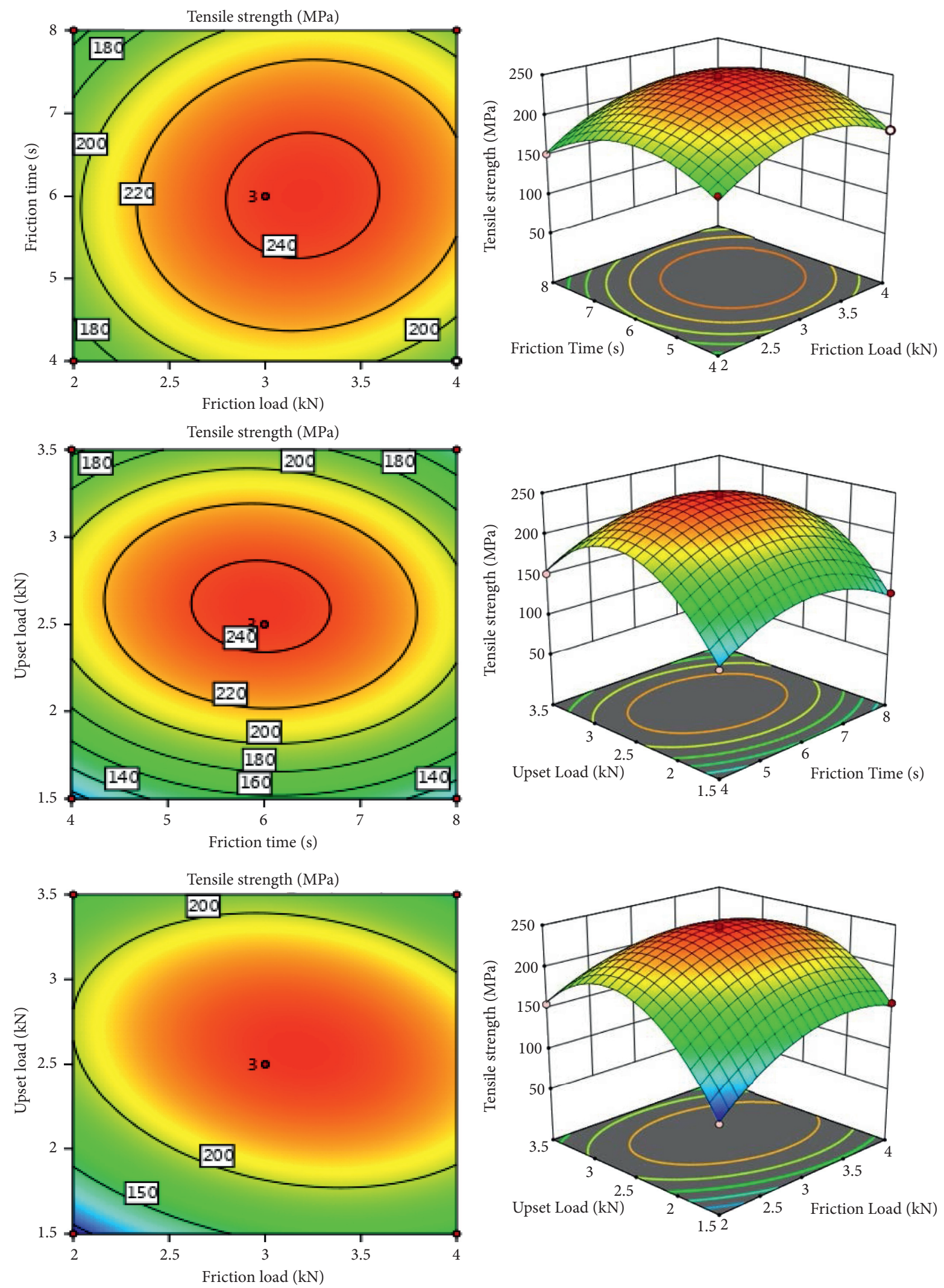

FIGURE 3: Contour and surface plots representing the parameter effect on TS. 
TABLE 6: Testament results.

\begin{tabular}{llccccc}
\hline \multirow{2}{*}{ Trail no. } & \multicolumn{3}{c}{ Parameters range } & \multicolumn{2}{c}{ TS (MPa) } & Deviation \% \\
& $f$ & $T$ & $P$ & Experimentally evaluated & Empirically calculated & 227.3 \\
3 & 4 & 6 & 2.5 & 226.5 & 220.89 & 0.37 \\
3 & 3 & 4 & 2.5 & 222.3 & 198.03 & -1.51 \\
\hline
\end{tabular}
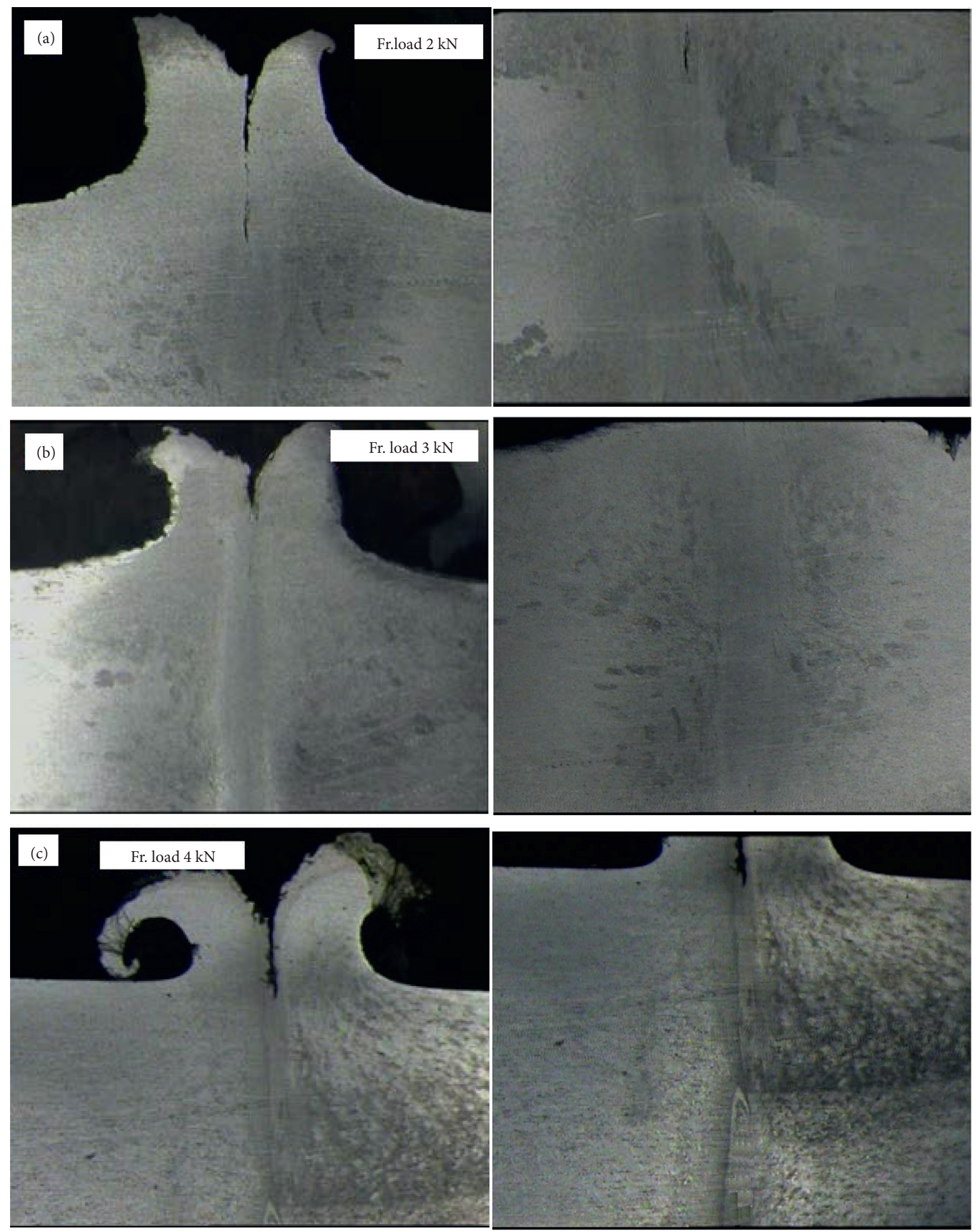

Figure 4: $(\mathrm{a}-\mathrm{c})$ Macroimage of the FW AA6063-T6 joint at various friction loads. 

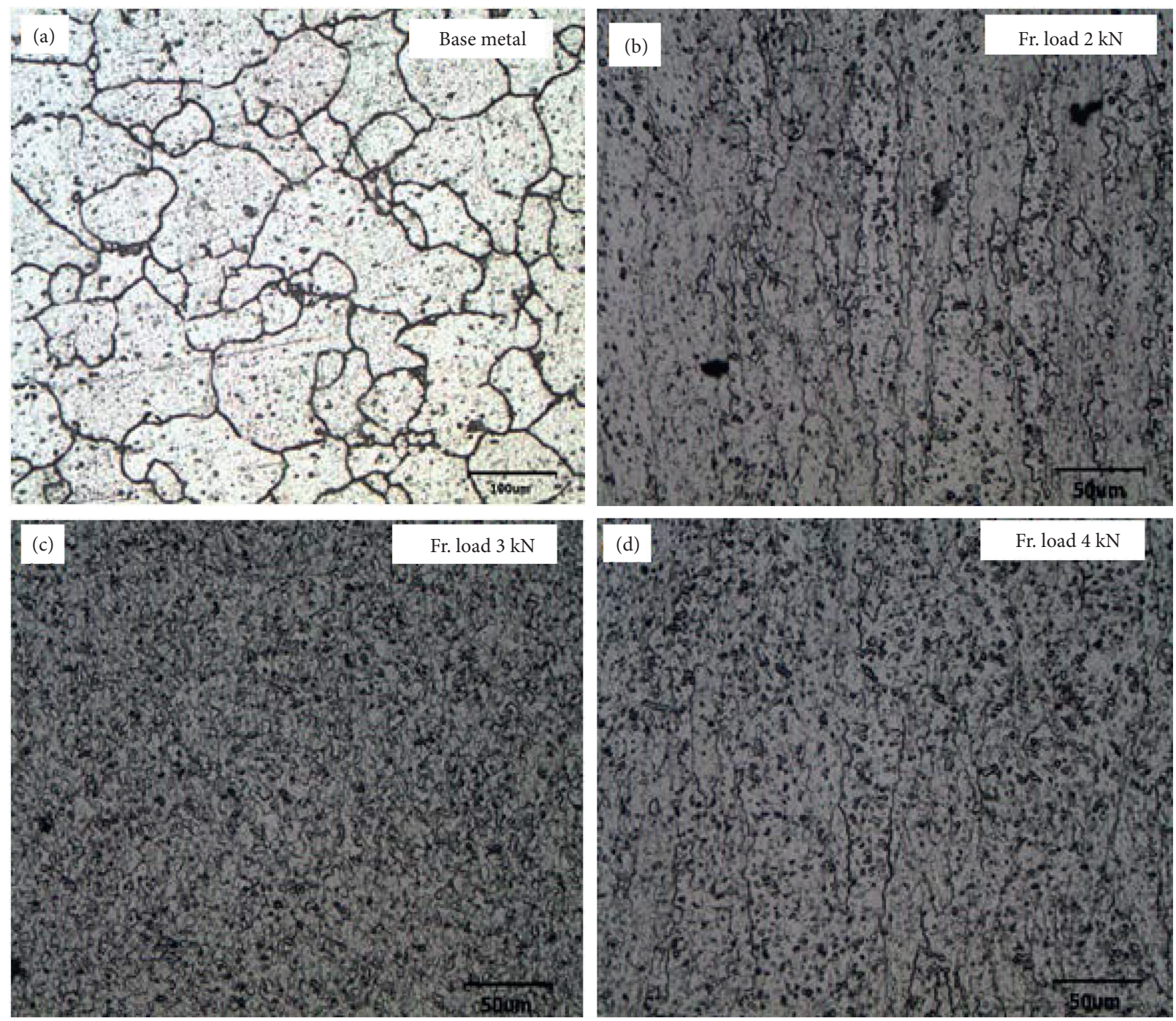

Figure 5: (a-d) Microimage of the parent metal and the FW AA6063-T6 joint at various friction loads.

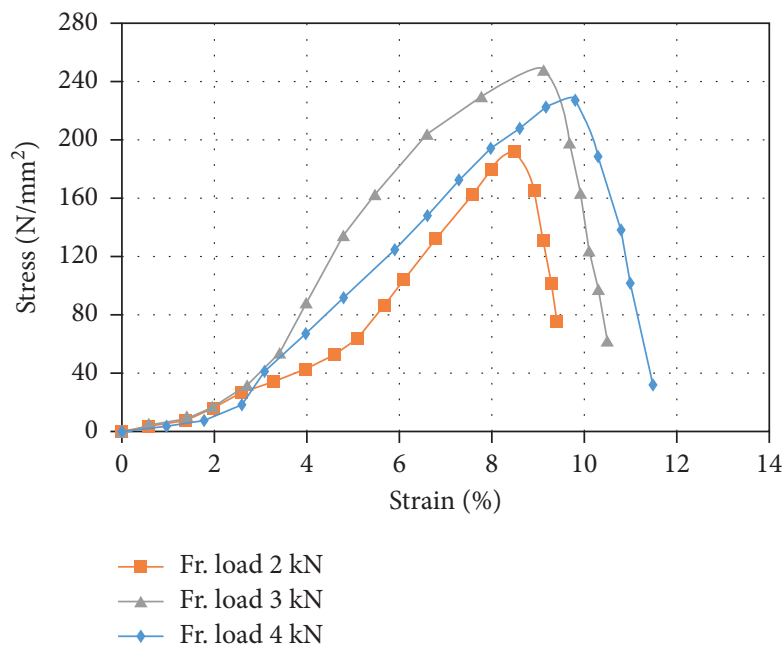

FIGURE 6: Stress-strain curve at various friction loads. 


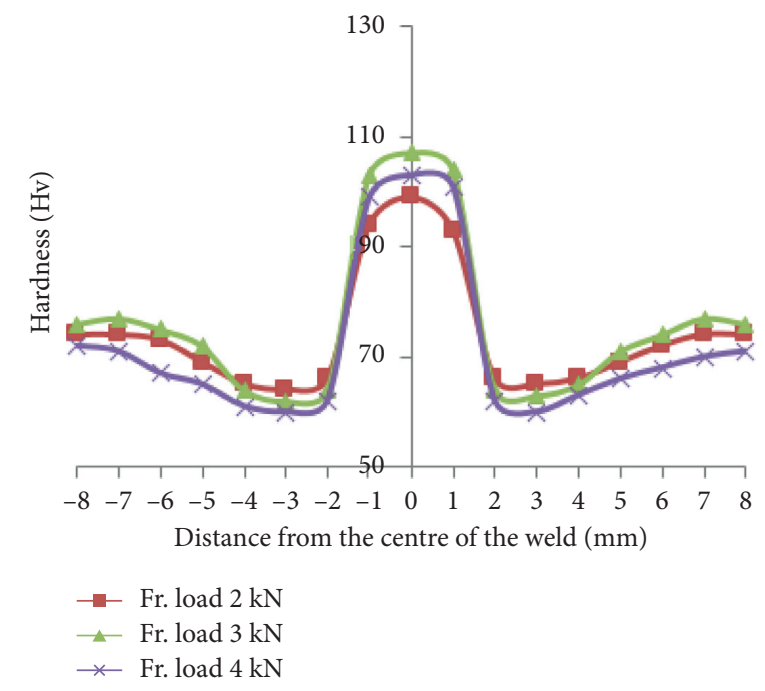

Figure 7: Hardness across the joint at various friction loads.
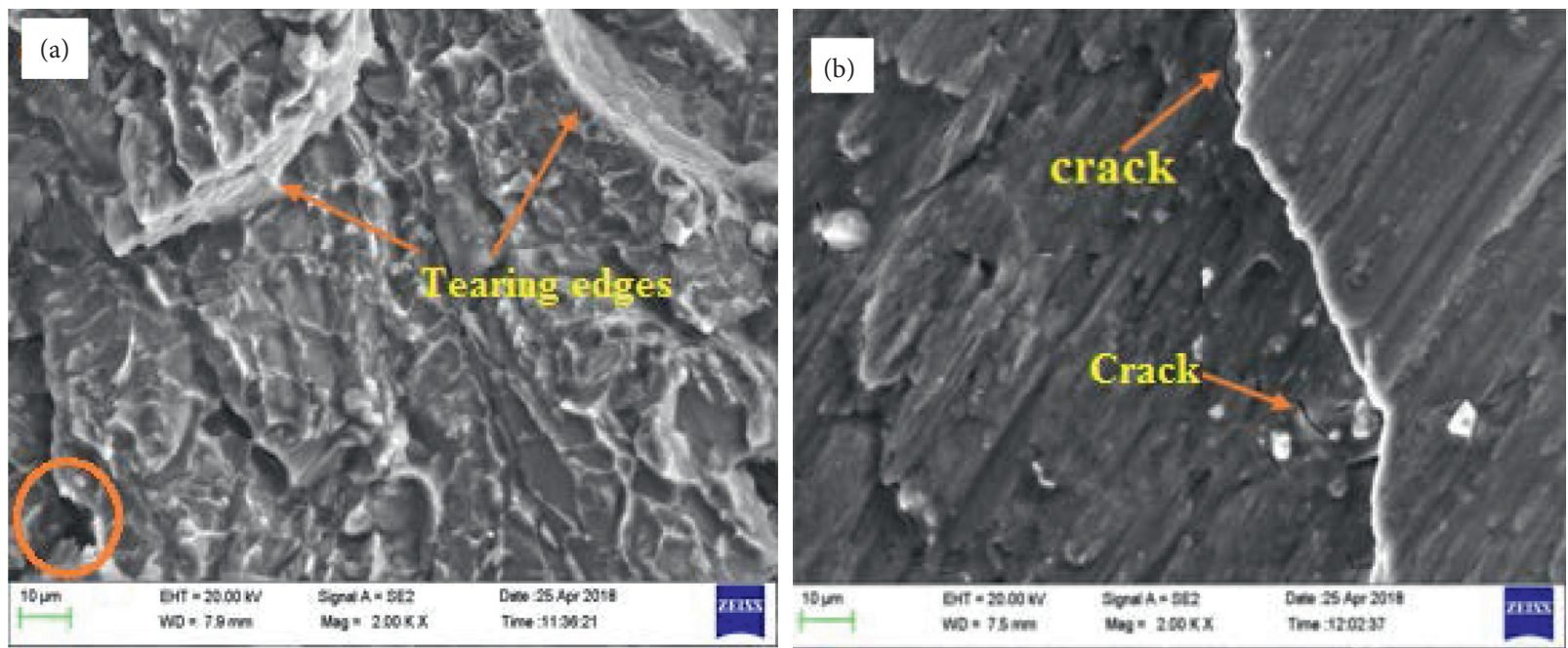

Figure 8: SEM fracture image. (a) Parent metal. (b) Joint welded at the optimized conditions.

The hardness measured across the AA6063 joint fabricated by FW at various friction loads is depicted in Figure 7. Due to the grain refinement during the welding process, the weld zone records the maximum hardness when compared to the parent metals. Despite the higher hardness, the fracture location was found in the weld zone at a lower friction load due to the minor crack in the weld line. In addition, the hardness of $108 \mathrm{HV}$ measured in the $\mathrm{WZ}$ at an optimum friction load of $3 \mathrm{kN}$ was recorded as maximum as the appropriate heat input and its associated plasticized material was achieved at the middle level of the friction load. On the other hand, the excess heat input and delayed cooling are attributed to the coarse graining effect as a result of the drop in hardness across the joint at the higher frictional load of $4 \mathrm{kN}$. Meanwhile, the occurrence of grain fragments at the higher friction load is linked with the higher strength than that of the lower friction load, and it is in good agreement with the previous authors [16, 17]. Furthermore, the failure location was noticed in the region between the $\mathrm{WZ}$ and the base metal, which was referred to as the "heat-affected zone" when the joint was made at the middle load of $3 \mathrm{kN}$ and the higher friction load of $4 \mathrm{kN}$.

The variation in TS of the welded joint is interpreted with the help of the fractured morphology features. As per that, the SEM fracture image of the parent metal and the joint welded at the optimized conditions is presented in Figures 8(a) and 8(b). The extensive tearing edges are noticed in the AA6063-T6 parent metal along with the few grooves and fissures (Figure $8(\mathrm{a})$ ). The mode of failure in the parent metal is ductile in nature since the plastically deformed materials are attributed to forming many tearing edges. On the other hand, the welded joint is characterized by a few cracks, voids, and a relatively flat morphology with a cascade structure. Moreover, the orientation of metal deformation is along the welding direction. Furthermore, the fracture image shows the cascade structure morphology and the fracture surface features the transition mode of failure towards the brittle. However, the generation of 
recrystallization temperature during the welding process causes the microstructure to be reformed at the weld interface and is subsequently attributed to weakening the zone nearer the weld area that is endorsed with the lower TS when compared to the parent metal TS $[29,30]$.

\section{Conclusions}

The conclusion drawn from this investigation is as follows:

(1) The Box-Behnken design-based RSM is employed to form the numerical relationship among the FW variables for the AA6063-T6 joint with a higher confidence level. FW conditions such as friction load $(f)$ of $3 \mathrm{kN}$ along with friction time $(t)$ of $6 \mathrm{~s}$ and an upset load of $2.5 \mathrm{kN}$ are given as input to attain the highest TS of $248 \mathrm{MPa}$.

(2) Moreover, friction load $(f)$ is identified as the most persuading parameter on the TS since the TS value is highly fluctuating concerning the variation in the friction load.

(3) Despite the outer flash representing a high volume of materials at the high friction load, the fine bonding with finer grains is also noticed at the interface of the AA6063-T6 joint. This phenomenon indicates the dominant performance of grain fragments over than that of heat generation.

(4) The occurrence of grain reformation is a result of the higher hardness at the weld zone than that of the base metal. Moreover, the interface between the $\mathrm{WZ}$ and the base metal recorded lower hardness.

(5) The crack and voids are observed in the fracture morphology of the welded joint and flat surface with a cascade structure. This shows the transition mode of failure is ductile and brittle in nature.

\section{Data Availability}

The data used to support the findings of this study are included within the article.

\section{Conflicts of Interest}

The authors declare that there are no conflicts of interest regarding the publication of this study.

\section{Acknowledgments}

The publication is only for the academic purpose of Addis Ababa Science and Technology University, Ethiopia.

\section{References}

[1] M. Bakkiyaraj, P. Palanisamy, and V. Balasubramanian, "Effect of post weld heat treatment on tensile strength and microstructure characteristics in dissimilar friction welded (AA6061 - AA7075-T6) joints," Materials Research Express, vol. 6 , no. 1205 , pp. 1-12, 2020.

[2] K. V. Reddy, R. B. Naik, G. R. Rao, G. M. Reddy, and R. A. Kumar, "Microstructure and damping capacity of
AA6061/graphite surface composites produced through friction stir processing," Composites Communications, vol. 20, no. 100352, 2020.

[3] P. Venkateshwar Reddy, P. R. Prasad, D. Mohana Krishnudu, and E. Venugopal Goud, "An investigation on mechanical and wear characteristics of $\mathrm{Al} 6063 / \mathrm{TiC}$ metal matrix composites using RSM," Journal of Bio- and Tribo-corrosion, vol. 5, no. 90, 2019.

[4] X. G. Chen, M. d. Silva, P. GougeonL, and S. t. Georges, "Microstructure and mechanical properties of friction stir welded AA6063-B4C metal matrix composites," Materials Science and Engineering: A, vol. 518, no. 1-5, pp. 174-184, 2009.

[5] K. S. Sreenivasan, S. Satish Kumar, and J. Katiravan, "Genetic algorithm based optimization of friction welding process parameters on AA7075-SiC composite," Engineering Science and Technology, an International Journal, vol. 22, no. 4, pp. 1136-1148, 2019.

[6] P. Sathiya, S. Aravindan, and A. Noorul Haq, "Effect of friction welding parameters on mechanical and metallurgical properties of ferritic stainless steel," The International Journal of Advanced Manufacturing Technology, vol. 31, no. 11-12, pp. 1076-1082, 2007.

[7] MTI Friction welding university: https://www.mtiwelding. $\mathrm{com} /$ parts/?geometries=tube-to-bar.

[8] X. Li, J. Li, Z. Liao, F. Jin, J. Xiong, and J. Xiong, "Effect of rotation speed on friction behavior and radially non-uniform local mechanical properties of AA6061-T6 rotary friction welded joint," Journal of Adhesion Science and Technology, vol. 32, no. 18, pp. 1987-2006, 2018.

[9] S. J. S. Chelladurai, K. Murugan, A. P. Ray, M. Upadhyaya, V. Narasimharaj, and S. Gnanasekaran, "Optimization of process parameters using response surface methodology: A review," Materials Today: Proceedings, vol. 37, no. 2, pp. 1301-1304, 2021.

[10] M. Bakkiyaraj, "Finding the optimum concentration of silicon carbide and graphite particles on the tensile strength, hardness and wear properties of aluminium matrix composites by RSM approach," Surface Topography Metrology and Properties, vol. 9, pp. 1-12, Article ID 025018, 2021.

[11] S. Gnanasekaran, G. Padmanaban, V. Balasubramanian, H. Kumar, and S. K. Albert, "Optimizing the laser parameters to attain maximum hardness in nickel based hardfacing surfaces," Journal of the Mechanical Behavior of Materials, vol. 26, no. 2-3, pp. 113-126, 2017.

[12] S. Gnanasekaran, G. Padmanaban, and V. Balasubramanian, "Effect of laser power on metallurgical, mechanical and $\mathrm{t}$ characteristics of h surfaces of nickel-based Alloy," Lasers in Manufacturing and Materials Processing, vol. 4, no. 4, pp. 178-192, 2017.

[13] R. Paventhan, P. R. Lakshminarayanan, and V. Balasubramanian, "Prediction and optimization of friction welding parameters for joining aluminium alloy and stainless steel," Transactions of Nonferrous Metals Society of China, vol. 21, no. 7, pp. 1480-1485, 2011.

[14] B. Balta, A. A. Arici, and M. Yilmaz, "Optimization of process parameters for friction weld steel tube to forging joints," Materials \& Design, vol. 103, pp. 209-222, 2016.

[15] A. K. Lakshiminarayanan and V. Balasubramanian, "Comparison of RSM with ANN in predicting tensile strength of friction stir welded AA7039 aluminum alloy joints," Transactions of Nonferrous Metals Society of China, vol. 19, pp. 9-18, 2009. 
[16] M. Bakkiyaraj, G. Saikrishnan, and V. Balasubramanian, "Estimating the mechanical properties of friction welded AISI 410 MSS joints using empirical relationship," Metallurgical Research \& Technology, vol. 117, no. 6, pp. 1-8, Article ID 618, 2020.

[17] R. Palanivel, R. F. Laubscher, and I. Dinaharan, "An investigation into the effect of friction welding parameters on tensile strength of titanium tubes by utilizing an empirical relationship," Measurement, vol. 98, pp. 77-91, 2017.

[18] M. Kimura, K. Suzuki, M. Kusaka, and K. Kaizu, "Effect of friction welding condition on joining phenomena and mechanical properties of friction welded joint between 6063 aluminium alloy and AISI 304 stainless steel," Journal of Manufacturing Processes, vol. 26, pp. 178-187, 2017.

[19] V. Gunaraj and N. Murugan, "Application of response surface methodology for predicting weld bead quality in submerged arc welding of pipes," Journal of Materials Processing Technology, vol. 88, no. 1-3, pp. 266-275, 1999.

[20] M. Hourmand, A. A. D. Sarhan, S. Farahany, and M. Sayuti, "Microstructure characterization and maximization of the material removal rate in nano-powder mixed EDM of AlMg2Si metal matrix composite-ANFIS and RSM approaches," The International Journal of Advanced Manufacturing Technology, vol. 101, no. 9-12, pp. 2723-2737, 2018.

[21] S. Sivasankaran, K. R. Ramkumar, F. A. Al-Mufadi, and O. M. Irfan, "Effect of TiB2/gr hybrid reinforcements in $\mathrm{Al}$ 7075 matrix on sliding wear behavior a by response surface methodology," Metals and Materials International, vol. 27, no. 6, pp. 1739-1755, 2021.

[22] M. Bakkiyaraj, P. Palanisamy, and V. Balasubramanian, "Evaluating the tensile strength of friction welded (AA6061 \& AA7075-T6) dissimilar joints by using response surface methodology," Materials Research Express, vol. 6, no. 8, pp. 1-12, 2019.

[23] E. Maleki, O. Unal, and K. Reza Kashyzadeh, "Influences of shot peening parameters on mechanical properties and fatigue behavior of $316 \mathrm{~L}$ steel: Experimental, taguchi method and response surface methodology," Metals and Materials International, 2021.

[24] S. Gnanasekaran, S. J. S. Chelladurai, T. Ramakrishnan et al., "Optimizing the characteristics of the laser hardfacing process parameters to maximize the wear resistance of Ni-based hardfaced deposits using the RSM technique," Advances in Materials Science and Engineering, vol. 2021, pp. 1-15, 2021.

[25] S. Gnanasekaran, S. J. S. Chelladurai, G. Padmanaban, and R. Arthanari, "Developing an empirical relationship to predict the wear characteristics of Ni-based hardfaced deposits on nuclear grade 316LN austenitic stainless steel," Advances in Materials Science and Engineering, vol. 2021, pp. 1-10, 2021.

[26] O. T. Midling and $\varnothing$. Grong, "A process model for friction welding of $\mathrm{Al} \mathrm{Mg} \mathrm{Si} \mathrm{alloys} \mathrm{and} \mathrm{Al} \mathrm{SiC} \mathrm{metal} \mathrm{matrix} \mathrm{com-}$ posites-I. Haz temperature and strain rate distribution," Acta Metallurgica et Materialia, vol. 42, no. 5, pp. 1595-1609, 1994.

[27] S. A. Etesami, M. H. Enayati, F. Karimzadeh, and V. Rasta, "Investigating the properties of friction welded 2014 Aluminum joints prepared with different rotational speeds," Transactions of the Indian Institute of Metals, vol. 68, no. 3, pp. 479-489, 2015.

[28] Y. Zhou, J. Zhang, T. H. North, and Z. Wang, "The mechanical properties of friction welded aluminium-based metal-matrix composite materials," Journal of Materials Science, vol. 32, no. 14, pp. 3883-3889, 1997.

[29] S. Gnanasekaran, G. Padmanaban, V. Balasubramanian, H. Kumar, and S. K. Albert, "Correlation between travel speed, microstructure, mechanical properties and wear characteristics of Ni-based hardfaced deposits over 316LN austenitic stainless steel," High Temperature Materials and Processes, vol. 38, 2019.

[30] S. Gnanasekaran, G. Padmanaban, V. Balasubramanian, K. Hemant, and K. A. Shaju, "Laser hardfacing of colmonoy-5 (Ni-Cr-Si-B-C) powder onto 316LN austenitic stainless steel: effect of powder feed rate on microstructure," Mechanical Properties and Tribological Behavior Lasers in Engineering, vol. 42, no. 4-6, pp. 283-302, 2019. 